\title{
Cirrus cloud seeding has potential to cool climate
}

\author{
T. Storelvmo, ${ }^{1}$ J. E. Kristjansson, ${ }^{2}$ H. Muri, ${ }^{2}$ M. Pfeffer, ${ }^{2}$ D. Barahona, ${ }^{3}$ and A. Nenes ${ }^{4}$ \\ Received 16 October 2012; revised 18 December 2012; accepted 24 December 2012; published 15 January 2013.
}

[1] Cirrus clouds, thin ice clouds in the upper troposphere, have a net warming effect on Earth's climate. Consequently, a reduction in cirrus cloud amount or optical thickness would cool the climate. Recent research indicates that by seeding cirrus clouds with particles that promote ice nucleation, their lifetimes and coverage could be reduced. We have tested this hypothesis in a global climate model with a state-of-the-art representation of cirrus clouds and find that cirrus cloud seeding has the potential to cancel the entire warming caused by human activity from pre-industrial times to present day. However, the desired effect is only obtained for seeding particle concentrations that lie within an optimal range. With lower than optimal particle concentrations, a seeding exercise would have no effect. Moreover, a higher than optimal concentration results in an over-seeding that could have the deleterious effect of prolonging cirrus lifetime and contributing to global warming. Citation: Storelvmo T., J. E. Kristjansson, H. Muri, M. Pfeffer, D. Barahona and A. Nenes (2013), Cirrus cloud seeding has potential to cool climate, Geophys. Res. Lett., 40, 178-182, doi:10.1029/2012GL054201.

\section{Introduction}

[2] With the realization that Earth's climate is changing at a rapid pace, a number of mechanisms through which climate could artificially be stabilized have been proposed in the literature. Climate sensitivity, defined as the equilibrium surface temperature response to a doubling of atmospheric $\mathrm{CO}_{2}$, is poorly constrained, and very high climate sensitivities cannot currently be ruled out [Roe and Baker, 2007]. This, combined with what seems to be a difficult prospect of curbing anthropogenic $\mathrm{CO}_{2}$ emissions [Davis et al., 2010], the main cause of modern climate change, has led many to propose climate engineering as a cooling mechanism [Keith, 2001; Boyd, 2008]. Carbon capturing and sequestration is one example of climate engineering that would directly target the problem of rising atmospheric $\mathrm{CO}_{2}$ concentrations [Metz et al., 2005]. Another class of climate engineering proposals is often termed solar radiation management (SRM), because rather than reducing Earth's greenhouse effect, their purpose

\footnotetext{
${ }^{1}$ Department of Geology and Geophysics, Yale University, New Haven, Connecticut, USA.

${ }^{2}$ Department of Geoscience, University of Oslo, Oslo, Norway.

${ }^{3}$ Global Modeling and Assimilation Office, NASA Goddard Space Flight Center, Greenbelt, Maryland, USA.

${ }^{4}$ Schools of Chemical and Biomolecular Engineering and Earth and Atmospheric Sciences, Georgia Institute of Technology, Atlanta, Georgia, USA.

Correspondence author: T. Storelvmo, Department of Geology and Geophysics, Yale University, 210 Whitney Avenue, New Haven, CT 06511, USA. (trude.storelvmo@yale.edu)

(C)2012. American Geophysical Union. All Rights Reserved. 0094-8276/13/2012GL054201
}

is to increase Earth's albedo/reflectivity. SRM strategies include stratospheric sulphur injection, mimicking volcanic eruptions [Crutzen, 2006], and enhancement of marine stratocumulus cloud albedo via sea salt injection [Latham, 1990]. Both mechanisms have been the focus of many recent studies [Rasch et al., 2008; Wang et al., 2011], and several complications have been identified. Examples are changes to the local and regional hydrological cycles [Ricke et al., 2010], as well as stratospheric ozone depletion in the case of stratospheric sulphur injection [Tilmes et al., 2008]. Here we address a climate engineering mechanism that has so far not been tested: the perturbation of cirrus clouds to reduce their lifetime and optical thickness, thereby cooling Earth's climate.

[3] This idea was first put forth by Mitchell and Finnegan [2009] and builds on the fact that spontaneous freezing of liquid solution droplets requires high water vapor partial pressures that well exceed that of saturation with respect to a plane ice surface (i.e., supersaturation, $\mathrm{S}_{i}$ ). Spontaneous freezing of droplets is a stochastic process that is referred to as homogeneous nucleation [Koop et al., 2000].

[4] The homogeneous nucleation rate decreases with increasing temperature $(T)$, and for $T$ higher than about $-35^{\circ} \mathrm{C}$, homogeneous ice nucleation does not occur in the atmosphere [Pruppacher and Klett, 1997]. The presence of a substrate to facilitate the formation of tiny ice crystals can significantly lower the supersaturation required for ice formation, a process known as heterogeneous ice nucleation. Certain insoluble particles can provide such substrates in the atmosphere and are termed ice nuclei (IN). Examples of natural IN are mineral dust particles, as well as certain primary biological particles [Pruppacher and Klett, 1997]. Bismuth tri-iodide (BiI3) is an example of an artificial IN and has been suggested as cirrus seeding material [Mitchell and Finnegan, 2009]. It has been suggested that BiI3 can initiate freezing at a supersaturation as low as $5 \%$, while homogeneous ice nucleation requires a supersaturation of the order of $50 \%$ at typical cirrus temperatures. Due to the low concentration of IN in the upper troposphere (UT), homogeneous freezing is thought to dominate cirrus cloud formation [Karcher and Lohmann, 2003; Mitchell et al., 2011]. Hence, the addition of very efficient IN in the right concentration may result in fewer, larger ice crystals. The heterogeneously formed ice crystals would deplete water vapor as they grow and prevent the supersaturations required for the onset of homogeneous freezing. Larger ice crystals would reduce cirrus optical thickness and shorten cloud lifetimes through increased ice crystal sedimentation velocities. Both mechanisms would yield a smaller greenhouse effect (Figure 1). Mitchell and Finnegan [2009] proposed that the seeding material could be injected at cirrus levels by commercial aircraft. A background concentration of seeding material would build up, and cirrus clouds would form in an environment sufficiently enriched in IN for homogeneous freezing to be suppressed. 


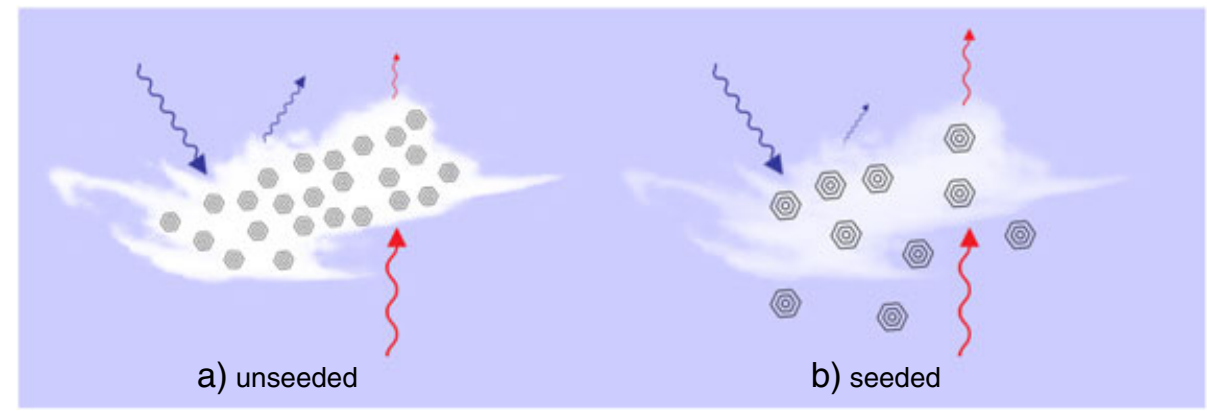

Figure 1. Conceptual schematic of changes in cirrus cloud properties in response to seeding. Red arrows represent longwave (LW) radiation and blue arrows represent shortwave $(\mathrm{SW})$ radiation. The seeded cirrus clouds on average reflect slightly less SW radiation back to space, but also allow more LW radiation to escape to space, and the latter effect dominates.

[5] Here we have tested the effect of background concentrations of seeding IN spanning several orders of magnitude in numerical simulations using a modified version of the National Center for Atmospheric Research Community Atmosphere Model (CAM, version 5).

\section{Modeling Tool and Experimental Setup}

[6] The CAM5 was, for the purpose of this study, run at a horizontal resolution of $1.9^{\circ}$ latitude and $2.5^{\circ}$ longitude, with 30 vertical levels, a finite volume dynamical core and a timestep of $20 \mathrm{~min}$. All simulations were conducted with climatological sea surface temperatures corresponding to the year 2000. CAM5's predecessor is described in Gent et al. [2011], but its cloud microphysics has since been updated [Gettelman et al., 2008, 2010] and it also has a recently developed modal aerosol treatment [Liu et al., 2012a]. The aerosol size distribution can now be represented by either three or seven lognormal modes (MAM3 and MAM7, respectively). The treatment of cirrus cloud microphysics in CAM5 has also been significantly improved relative to earlier versions [Liu et al., 2007], but was in this study partly replaced by an alternative and more flexible cirrus scheme, developed by Barahona and Nenes [2008, 2009]. The scheme is based on an analytical solution of the governing equations of a cooling air parcel. It explicitly accounts for the effect of cloud formation conditions and aerosol properties on the cirrus ice crystal concentration. Competition between homogeneous and heterogeneous ice nucleation, hence the influence of ice nuclei on ice crystal concentration, is also accounted for. Heterogeneous ice nucleation is described through a generalized ice nucleation spectrum, which can have any functional form, providing flexibility in describing ice nucleation on different IN. While the CAM5 cirrus scheme has already been carefully validated, particularly in terms of global cloud and radiation fields [Liu et al., 2012b; Gettelman et al., 2008, 2010], we show in Table 1 global averages of some key cloud and radiation fields for the standard CAM5, the modified CAM5 used in this study, as well as from observations. Both model versions were run with homogeneous nucleation only, for temperatures below $-38^{\circ} \mathrm{C}$. The introduction of the new cirrus scheme does not dramatically change the cloud and radiation fields. However, it does produce more ice crystals at cirrus levels, which leads to optically thicker and longer-lived cirrus clouds, hence the slightly larger ice and liquid water paths (the latter due to reduced accretion of liquid by falling ice crystals). Cirrus ice crystals concentrations lie in the range 10 $1000 \mathrm{~L}^{-1}$, with a global annual average at $200 \mathrm{hPa}$ of $\sim 400 \mathrm{~L}^{-1}$. This is somewhat higher than the concentrations reported for example from the recent SPARTICUS campaign [Mitchell et al., 2011], but values are very sensitive to the treatment of subgrid-scale vertical velocity (see section 3 ). Here, we made the assumption that under unseeded conditions, cirrus clouds form solely through homogeneous ice nucleation. The concentration of solution droplets that could potentially nucleate homogeneously corresponds to the predicted number concentration of particles in the Aitken mode of the MAM3 aerosol module.

[7] Based on the number concentration and size of the solution droplets, as well as temperature and vertical velocity, the homogeneous nucleation rate were calculated [Barahona and Nenes, 2008]. The seeding IN were all conservatively assumed to activate and nucleate ice at a supersaturation of 10\% [Mitchell et al., 2011]. We have carried out 20 model simulations, each 10 years of length after a spin-up of 3 months, in which the concentration of seeding IN in the UT $\left(\mathrm{IN}_{s}\right)$ was varied from 0 to $1500 \mathrm{~L}^{-1}$. Note that in the following, cirrus clouds refer to all clouds forming in the UT, which will here correspond to the part of the atmosphere with temperatures lower than $-38^{\circ} \mathrm{C}$.

\section{Results}

[8] The delivery method, dispersion, and atmospheric fate of the seeding IN are beyond the scope of the present study. Here, we focus on the effect of seeding on cirrus cloud properties and Earth's energy budget, under the assumption that there exist some means to build up uniform background concentrations of seeding IN in the UT. Figure 2a shows simulated global annual mean vertically integrated ice amount (ice water path, IWP) and high cloud coverage $\left(\mathrm{CC}_{H G H}\right)$, as a function of $\mathrm{IN}_{s}$. For low $\mathrm{IN}_{s}$ concentrations $\left(<5 \mathrm{~L}^{-1}\right)$, IWP and $\mathrm{CC}_{H G H}$ remain very similar to their values under pure

Table 1. Simulated Global and Annual Mean Cloud Cover (CC), Ice Water Path (IWP), Liquid Water Path (LWP), and Net Cloud Forcing (NCF) From the Standard and Modified CAM5.1 (CAM5.1-HOM and CAM5.1-BN09, Respectively) as well as From Satellite Observations (OBS) $\mathrm{K}^{\mathrm{a}}$

\begin{tabular}{lcccc}
\hline & $\mathrm{CC}(\%)$ & $\mathrm{IWP}\left(\mathrm{gm}^{-2}\right)$ & $\mathrm{LWP}\left(\mathrm{gm}^{-2}\right)$ & $\mathrm{NCF}\left(\mathrm{Wm}^{-2}\right)$ \\
\hline CAM5.1-HOM & 64.3 & 17.8 & 44.2 & -27.6 \\
CAM5.1-BN09 & 68.8 & 21.9 & 47.1 & -26.3 \\
OBS & 71 & $20-70$ & $30-50$ & -17.2 to -23.8
\end{tabular}

${ }^{a}$ Observations are taken from a combination of CloudSat and CALIPSO retrievals (CC, IWP, and LWP), and from ERBE and CERES (NCF). 


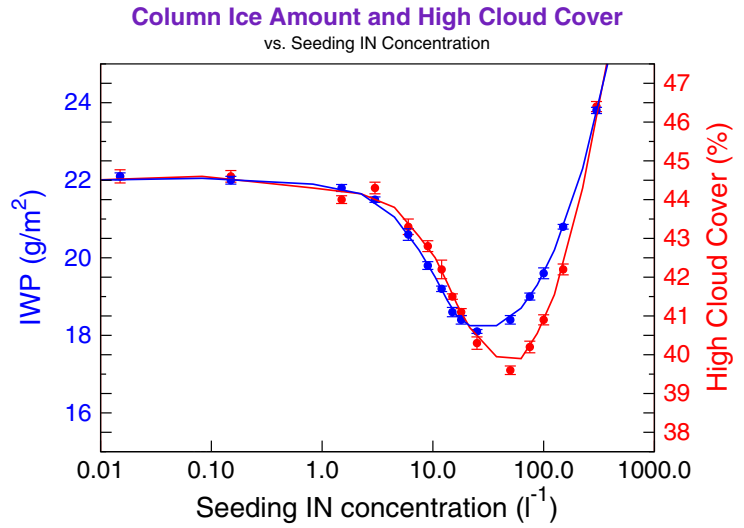

a)

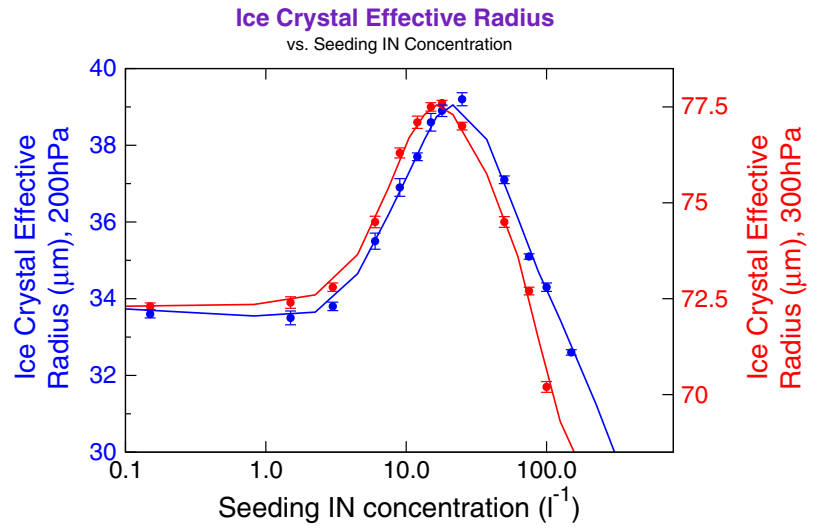

b)

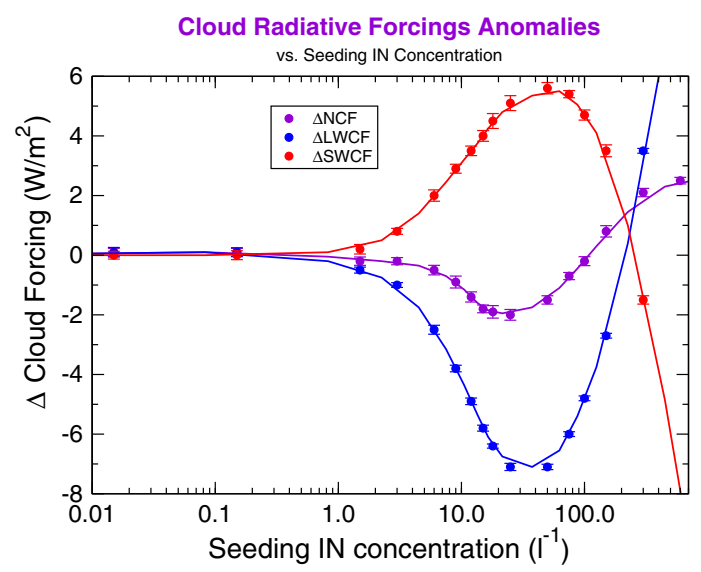

c)

Figure 2. CAM5 simulations of macro-physical and radiative properties of high clouds as a function of $\mathrm{IN}_{s}$. Each circle corresponds to an individual 10 year CAM5 simulation. (a) High cloud amount (i.e., cloud cover integrated from 400 to $50 \mathrm{hPa}$ ) and vertically integrated ice amount (ice water path, IWP), (b) ice crystal effective radius at $300 \mathrm{hPa}$ (red solid line) and $200 \mathrm{hPa}$ (blue solid line), and (c) changes in longwave, shortwave and net cloud forcing (SWCF, LWCF, and NCF, respectively) at the top of the atmosphere (TOA), relative to REF. Solid lines represent moving averages. Error bars represent one standard deviation, calculated based on annual averages.

homogeneous freezing, i.e., $\mathrm{IN}_{s}=0 \mathrm{~L}^{-1}$, our reference case (REF). However, for $\mathrm{IN}_{s}$ in the range $5-100 \mathrm{~L}^{-1}$, both are suppressed and ice crystals are 10-20\% larger than in the case of pure homogeneous freezing (Figure $2 \mathrm{~b}$ ). In this $\mathrm{IN}_{s}$ range, we also observed a small reduction in liquid water path, due to increased accretion of liquid by falling ice crystals. Finally, for $\mathrm{IN}_{s}>100 \mathrm{~L}^{-1}$, seeding leads to the opposite effect; smaller ice crystals and the consequent increase in IWP and $\mathrm{CC}_{H G H}$. From Figure 2, three distinct regimes can be identified: (1)the sub-optimal seeding regime- $-\mathrm{IN}_{s}$ is insufficient for suppression of homogeneous nucleation, and the cirrus clouds remain unaffected by the seeding; (2) the optimal seeding regime-homogeneous nucleation is suppressed, and $\mathrm{IN}_{s}$ is low enough to reduce ice crystal concentration and increase crystal size, with associated reductions in cirrus cloud amount and coverage; and (3) the over-seeding regimehomogeneous nucleation is suppressed, but more ice crystals nucleate on seeds than would otherwise have nucleated homogeneously in the unseeded case. Table 2 gives approximate $\mathrm{IN}_{s}$ intervals for these three regimes in our control model setup (CTL). As a consequence of the increase in ice crystal sizes and decrease in cirrus cloud amount in the optimal seeding regime, cirrus clouds become optically thinner, as illustrated by the reduction in longwave cloud forcing
(LWCF), shown in Figure 2c. The reduced LWCF allows for more outgoing longwave radiation at the top of the atmosphere (TOA), corresponding to a negative radiative forcing (i.e., cooling) of about $7 \mathrm{Wm}^{-2}$. This cooling is partly compensated for by a reduction in cirrus cloud albedo and hence the shortwave cloud forcing (SWCF), such that the maximum reduction in the net cloud forcing (NCF) amounts to $2.0 \mathrm{Wm}^{-2}$. While changes in the net shortwave flux at the TOA are very similar to the changes in SWCF, the reduction in UT water vapor in response to the seeding increases the outgoing longwave radiation further by up to $0.5 \mathrm{Wm}^{-2}$ and hence amplifies the cooling.

[9] Hence, cirrus cloud seeding could potentially eliminate a forcing equivalent to that which has been causing climate

Table 2. Approximate Sub-optimal, Optimal, and Over-seeding INs Concentrations for the CTL, $\mathrm{WW}_{c, L O W}$ and $\mathrm{W}_{c, H G H}$ Sets of Simulations

\begin{tabular}{lccc}
\hline Case & $\begin{array}{r}\text { Sub-optimal } \\
\mathrm{IN}_{s}\left(\mathrm{~L}^{-1}\right)\end{array}$ & $\begin{array}{r}\text { Optimal IN } \\
\left(\mathrm{L}^{-1}\right)\end{array}$ & $\begin{array}{r}\text { Over-seeding } \\
\mathrm{IN}_{s}\left(\mathrm{~L}^{-1}\right)\end{array}$ \\
\hline CTL & $<5$ & $5-100$ & $>100$ \\
$\mathrm{~W}_{c, L O W}$ & $<1$ & $1-25$ & $>25$ \\
$\mathrm{~W}_{c, H G H}$ & $<20$ & $20-200$ & $>200$ \\
\hline
\end{tabular}




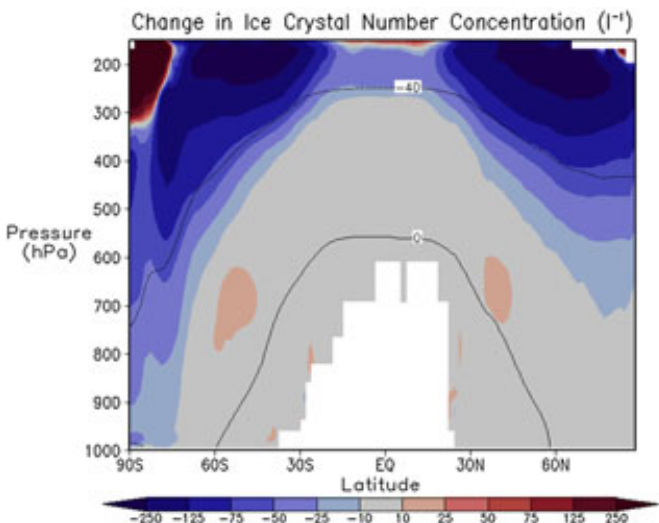

a)

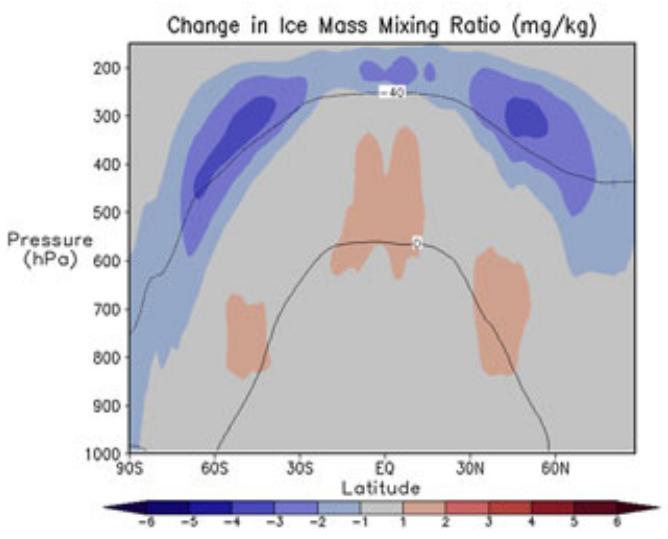

c)

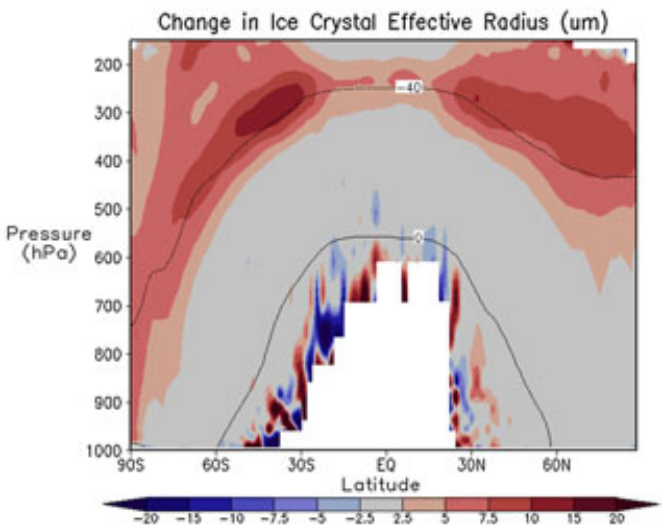

b)

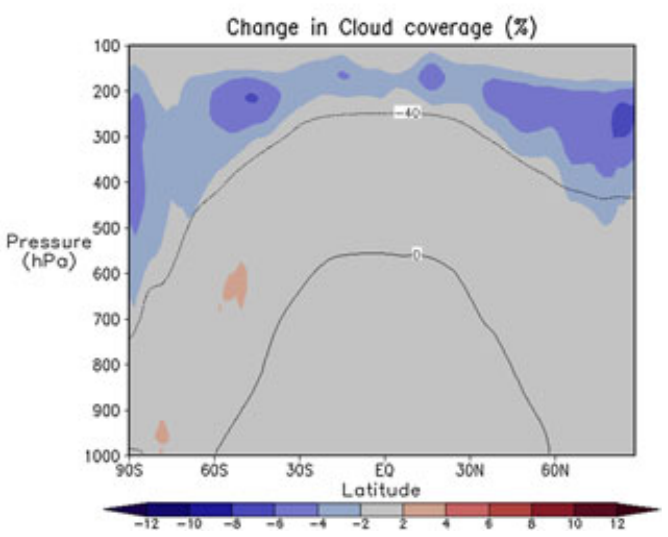

d)

Figure 3. Simulated changes in zonal and annual mean cloud properties induced by a seeding IN concentration of $151^{-1}$ (relative to REF): (a) in-cloud ice crystal number concentration, (b) ice crystal effective radius, (c) ice mass mixing ratio, and (d)cloud coverage. All plots are based on 10 year model simulations.

change to date. However, this would require seeding IN concentrations finely tuned to lie exactly in the optimal $\mathrm{IN}_{S}$ window. While the main perceived risk of under-seeding is a costly, wasted effort, over-seeding could actually lead to the opposite of the desired effect. This is illustrated in Figure 2; $\mathrm{IN}_{s}$ concentrations larger than $100 \mathrm{~L}^{-1}$ would lead to an increase in IWP and a decrease in ice crystal sizes relative to the unseeded atmosphere, and hence a warming rather than a cooling. Based on Figure 2, we have approximated the optimal $\mathrm{IN}_{s}, \mathrm{IN}_{s, o}$, to $15 \mathrm{~L}^{-1}$ and have displayed anomalies in several cirrus cloud properties relative to $\mathrm{REF}$ for $\mathrm{IN}_{s, o}$ in Figure 3. Evident is the strong reduction in ice crystal number concentrations in the UT (Figure 3a), which allows individual ice crystals to grow larger via vapor deposition (Figure $3 b$ ). The larger ice crystals in turn lead to reduced cloud ice (Figure 3c) and cloud coverage (Figure 3d), as a result of the faster sedimentation of the larger ice crystals. As expected, the strongest perturbations are found at mid-latitudes, where cirrus clouds form in situ, rather than in the tropics, where anvil cirrus are produced by convective outflow.

[10] Several studies have indicated that the relative importance of homogeneous versus heterogeneous ice nucleation is very sensitive to the vertical velocity at the cloud-scale [Karcher and Lohmann, 2003; DeMott et al., 1997]. CAM5 parameterizes this subgrid-scale updraft velocity as a single value for each model grid box, proportional to the square root of the turbulent kinetic energy (TKE), $W_{c}=\sqrt{\frac{2}{3} T K E}$.
[11] We have tested the robustness of our results to increased/ decreased vertical velocities, by repeating the set of $\mathrm{IN}_{s}$ perturbation simulations, but with $W_{c}=W_{c, H G H}=\sqrt{\frac{8}{3} T K E}$ and $W_{c}=W_{c, L O W}=\sqrt{\frac{1}{6} T K E}$, respectively. Figure 4 shows

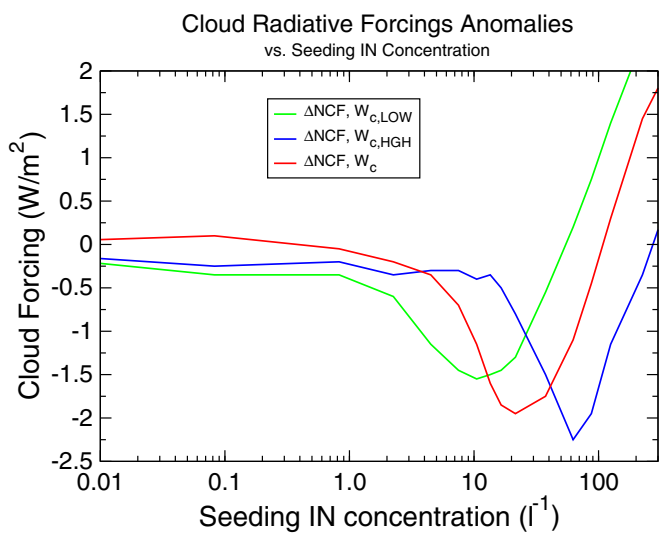

Figure 4. Change in the net cloud forcing (NCF) as a function of $\mathrm{IN}_{s}$ at the TOA relative to REF for default, doubled and halved subgrid-scale vertical velocity $\left(\mathrm{W}_{c}, \mathrm{~W}_{c, H G H}\right.$, $\mathrm{W}_{c, \text { LOW}}$, respectively). 
the change in NCF (relative to REF) as a function of $\mathrm{IN}_{s}$ for simulations with $W_{c}, W_{c, H G H}$, and $W_{c, L O W}$. Evident from Table 1 is a shift in the optimal $\mathrm{IN}_{s}$ interval toward lower (higher) values when $\mathrm{W}_{c}$ is decreased (increased). The magnitude of the cooling is also affected, and becomes smaller (larger) when $\mathrm{W}_{c}$ is decreased (increased). Higher vertical velocities lead to higher homogeneous nucleation rates, and hence a stronger perturbation when homogeneous nucleation is suppressed. Higher vertical velocities also require higher $\mathrm{IN}_{s}$ concentrations in order for homogeneous nucleation to be suppressed. While previous studies of the effect of anthropogenic IN on cirrus have reported a sensitivity to the concentration of solution droplets available for homogeneous nucleation [Penner et al., 2009], we found minor changes in a simulation reducing the concentration of solution droplets available by $50 \%$.

\section{Discussion and Outlook}

[12] Further investigations of the viability of cirrus seeding as a means of stabilizing Earth's climate will require simulations of the atmospheric lifetimes of seeding IN, from the point of emission, through potential ice nucleation, and subsequent sedimentation and deposition on Earth's surface. Laboratory investigations of ice nucleation on $\mathrm{BiI} 3$ are also required to shed further light on the geoengineering process investigated here. The present study has demonstrated that successful cirrus cloud seeding requires seeding IN concentrations that lie in a relatively narrow optimal interval. The bounds of this interval are set by the vertical velocities in the UT, for which only sparse and sporadic measurements exist. A premature implementation of cirrus seeding before knowledge of vertical velocities at cirrus levels is improved could accelerate global warming as opposed to prevent it.

[13] Acknowledgments. The work presented in this paper was supported in part by the facilities and staff of the Yale University Faculty of Arts and Sciences High Performance Computing Center. The Research Council of Norway, through grant number 216763/F11, made this collaboration possible, and H. M. and M. P. were supported through the grants $184714 / \mathrm{S} 30$ and 207711/E10. T.S. is thankful to B. Dobbins (Yale University) for technical support and to J. Wettlaufer (Yale University) for helpful comments.

\section{References}

Barahona, D. and A. Nenes (2008), Parameterization of cirrus cloud formation in large-scale models: Homogeneous nucleation. J. Geophys. Res.-Atmos. 113, doi:10.1029/2007jd009355.

Barahona, D. and A. Nenes (2009), Parameterizing the competition between homogeneous and heterogeneous freezing in ice cloud formationpolydisperse ice nuclei, Atmos. Chem. Phys 9, 5,933-5,948.

Boyd, P. W. (2008), Ranking geo-engineering schemes, Nat. Geosci. 1, $722-724$.

Crutzen, P. J. (2006), Albedo enhancement by stratospheric sulfur injections: A contribution to resolve a policy dilemma? Clim. Chang. $77,211-219$.
Davis, S. J., K. Caldeira, and H. D. Matthews (2010), Future $\mathrm{CO}_{2}$ emissions and climate change from existing energy infrastructure, Science 329, doi: $10.1126 /$ Science. 1188566 .

DeMott, P. J., D. C. Rogers and S. M. Kreidenweis (1997), The susceptibility of ice formation in upper tropospheric clouds to insoluble aerosol components, J. Geophys. Res.-Atmos. 102, 19,575-19,584.

Gent, P. R., G. Danabasoglu, L. J. Donner, M. M. Holland, E. C. Hunke, S. R. Jayne, D. M. Lawrence, R. B. Neale, P. J. Rasch, M. Vertenstein, P. H. Worley, Z. L. Yang and M. H. Zhang (2011), The Community Climate System Model Version 4, J. Climate 24, 4,973-4,991.

Gettelman, A., H. Morrison and S. J. Ghan (2008), A new two-moment bulk stratiform cloud microphysics scheme in the community atmosphere model, version 3 (CAM3). Part II: Single-column and global results, J. Climate 21, 3,660-3,679.

Gettelman, A., X. Liu, S. J. Ghan, H. Morrison, S. Park, A. J. Conley, S. A. Klein, J. Boyle, D. L. Mitchell and J. F. L. Li (2010), Global simulations of ice nucleation and ice supersaturation with an improved cloud scheme in the Community Atmosphere Model. J. Geophys. Res.-Atmos, 115, doi:10.1029/2009jd013797.

Karcher, B. and U. Lohmann (2003), A parameterization of cirrus cloud formation: Heterogeneous freezing, J. Geophys. Res.-Atm. 108, doi:10.1029/ 2002 jd003220.

Keith, D. W. (2001), Geoengineering, Nature 409, 420-420.

Koop, T., B. P. Luo, A. Tsias and T. Peter (2000), Water activity as the determinant for homogeneous ice nucleation in aqueous solutions, Nature 406, 611-614.

Latham, J. (1990), Control of Global Warming, Nature 347, 339-340.

Liu, X., J. E. Penner, S. J. Ghan and M. Wang (2007), Inclusion of ice microphysics in the NCAR Community Atmospheric Model Version 3 (CAM3), J. Climate 20, 4,526-4,547.

Liu, X., R. S. Easter, S. J. Ghan, R. Zaveri, P. Rasch, X. Shi, J.-F. Lamarque, A. Gettelman, H. Morrison, F. Vitt, A. Conley, S. Park, R. Neale, C. Hannay, A. M. L. Ekman, P. Hess, N. Mahowald, W. Collins, M. J. Iacono, C. S. Bretherton, M. G. Flanner and D. Mitchell (2012a), Toward a minimal representation of aerosols in climate models: Description and evaluation in the Community Atmosphere Model CAM5, Geosci. Model Dev. 5, 709-739.

Liu, X., X. Shi, K. Zhang, E. J. Jensen, A. Gettelman, D. Barahona, A. Nenes and P. Lawson (2012b), Sensitivity studies of dust ice nuclei effect on cirrus clouds with the Community Atmosphere Model CAM5. Atmos. Chem. Phys. Disc. 12, 13,119-13,160.

Metz, B., Davidson, O., de Coninck, H., Loos, M. and Meyer, L. (2005), IPCC Report on Carbon Capture and Sequestration, Cambridge, UK.

Mitchell, D. L. and W. Finnegan (2009), Modification of cirrus clouds to reduce global warming, Environ. Res. Lett. 4, doi:10.1088/1748-9326/4/ 4/045102.

Mitchell, D. L., S. Mishra and R. P. Lawson (2011), Cirrus clouds and climate engineering: New findings on ice nucleation and theoretical basis, in Planet Earth 2011-Global Warming Challenges and Opportunities for Policy and Practice, ed E. G. Caravannis Ch. 12, InTech.

Penner, J. E., Y. Chen, M. Wang and X. Liu (2009), Possible influence of anthropogenic aerosols on cirrus clouds and anthropogenic forcing, Atmos. Chem. Phys., 9, 879-896.

Pruppacher, H. R. and J. D. Klett (1997), Microphysics of Clouds and Precipitation, 2nd ed., Kluwer Academic, Norwell, Massachusetts.

Rasch, P. J., P. J. Crutzen and D. B. Coleman (2008), Exploring the geoengineering of climate using stratospheric sulfate aerosols: The role of particle size, Geophys. Res. Lett. 35, doi:10.1029/2007gl032179.

Ricke, K. L., G. Morgan and M. R. Allen (2010), Regional climate response to solar-radiation management, Nat. Geosci. 3, 537-541.

Roe, G. H. and M. B. Baker (2007), Why is climate science so unpredictable, Science 318, doi:10.1126/Science.1144735 (2007).

Tilmes, S., R. Muller and R. Salawitch (2008), The sensitivity of polar ozone depletion to proposed geoengineering schemes, Science 320, 1,201-1,204.

Wang, H., Rasch, P. J. and Feingold, G. (2011), Manipulating marine stratocumulus cloud amount and albedo: a process-modelling study of aerosol-cloud-precipitation interactions in response to injection of cloud condensation nuclei, Atmos. Chem. Phys. 11, 4,237-4,249. 